\title{
Sleep Smart. Get a Life
}

By Christiaan Geldenhuys. Pp. xvi + 256. R130. Rollerbird Press.

2003. ISBN 1-919780-54-8.

This book is a comprehensive and informative text on the subject of sleep and anything that has to do with it.

It is a relatively easy-to-read text, and each page is packed with facts. The book covers a wide variety of subjects surrounding sleep, including sleep disorders, self-help guidance to a healthier sleeping pattern, eating/nutritional information, etc. It is medically and factually sound, and should be easy reading for the general public, possibly saving people from visiting their general practitioner unnecessarily for everyday sleeping problems.

It is indeed a good and descriptive book, sometimes repeating itself, but useful for those who want to know about the mysteries of sleep and for understanding their problems and difficulties. Some very topical issues such as longdistance travelling and sleep apnoea are discussed as well. Another important subject, that of sleep medication, is looked at and the author also gives valuable information on herbal remedies.

I can recommend this book, mostly for general public use, but even your not-so-informed general practitioner might benefit.

\section{Sandra Brink}

